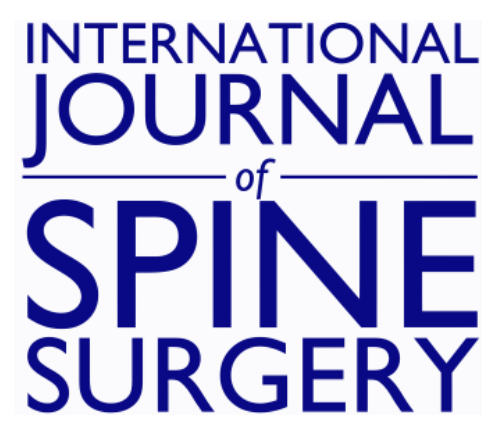

\title{
Expandable Interbody Fusion Cages: An Editorial on the Surgeon's Perspective on Recent Technological Advances and Their Biomechanical Implications
}

Kai-Uwe Lewandrowski, Lisa Ferrara and Boyle Cheng

Int J Spine Surg 2020, 14 (s3) S56-S62

doi: https://doi.org/10.14444/7127

http://ijssurgery.com/content/14/s3/S56

This information is current as of April 26, 2023.

Email Alerts Receive free email-alerts when new articles cite this article. Sign up at: http://ijssurgery.com/alerts 


\title{
Expandable Interbody Fusion Cages: An Editorial on the Surgeon's Perspective on Recent Technological Advances and Their Biomechanical Implications
}

\author{
KAI-UWE LEWANDROWSKI, MD, ${ }^{1}$ LISA FERRARA, PHD ${ }^{2}$ BOYLE CHENG, PHD $^{3}$ \\ ${ }^{1}$ Center for Advanced Spine Care of Southern Arizona and Surgical Institute of Tucson, Arizona, Department of Orthopaedics, Fundación Universitaria Sanitas, \\ Bogotá, Colombia, Department of Neurosurgery, Universidade Federal do Estado do Rio de Janeiro, Rio de Janeiro, Brazil, ${ }^{2}$ OrthoKinetic Technologies LLC, \\ Southport, North Carolina, ${ }^{3}$ Carnegie Mellon University, Neurosurgical and Spine Research, Allegheny General Hospital, Pittsburgh, Pennsylvania
}

\begin{abstract}
Background: Expandable cages have gone through several iterations since they first appeared on the market in the early 2000s. Their development was prompted by some common problems associated with static interbody cages, including migration, expulsion, dural or neural traction injury, and pseudarthrosis.

Objective: To summarize current technological advances from earlier expandable lumbar interbody fusion devices to implants with vertical and medial-to-lateral expansion mechanisms.

Methods: The authors review the currently available expandable cage designs, the incremental technological advances, and how these devices impact minimally invasive surgery interbody procedures and clinical outcomes. The strategic concepts intended to improve the minimally invasive application of expandable interbody fusion implants are reviewed from a surgeon's perspective in a clinical context to discuss how their use may improve patient outcomes.

Conclusions: The geometrical configuration, effective stiffness of composite multi-material cage designs may impact the bone-implant contact area with the endplates. Hybridization strategies of expandable cage technology with modern minimally invasive and endoscopic spinal surgery techniques are presented by outlining their advantages and disadvantages.
\end{abstract}

Level of Evidence: 1

Clinical Relevance: Systematic review.

Special Issue

Keywords: interbody fusion, cage, expandable

\section{INTRODUCTION}

This special issue of the International Journal of Spine Surgery is focused on demonstrating the clinical application of endoscopic and other minimally invasive spinal surgeries (MISSs) beyond the scope of simple decompression by adopting state-ofthe-art technologies. Treatment of many common degenerative conditions requires the use of an implant to aid in the stabilization of the lumbar spine. The combination of endoscopy with interspinous process implants is an example of posterior column stabilization ${ }^{1}$ demonstrated in this special focus issue. Anterior column stabilization is integral to many modern reconstructive fusion procedures. Successful endoscopic implantation of interbody fusion cages through the transforaminal approach for anterior column stabilization has been described in several studies, ${ }^{2-5}$ some as standalone fusions ${ }^{5,6}$ and others as endoscopically assisted placement of interbody fusion cages with posterior supplemental fixation..$^{2-4}$ In this editorial, the authors review contemporary design rationales and comparative biomechanical concepts for static and expandable lumbar interbody fusion cages and how they relate to clinical outcomes.

\section{SIMPLIFIED SPINE CARE}

Coupling modern interbody fusion cages with minimally invasive implantation techniques is attractive as it facilitates less invasive spinal fusion further and enables the evolution from traditional open surgery to other types of translaminar MISS or even transforaminal endoscopic techniques. ${ }^{6}$ Nowadays, there is an ongoing transition of appropriately selected spine surgeries from the hospital into an outpatient ambulatory surgery 
center setting. ${ }^{7,8}$ Hence, less traumatic, less complicated, and less painful surgeries with reliable outcome improvements are needed to facilitate this transition. ${ }^{9}$ Expandable interbody fusion cages have the potential to play a role in the outpatient ambulatory spinal decompression fusion surgery solution. ${ }^{5}$

\section{WHY EXPANDABLE CAGE DESIGNS?}

Historically, interbody fusion cages were introduced to improve fusion rates and to restore lumbar lordosis, as well as intervertebral and foraminal height. ${ }^{10-12}$ Additional advantages relate to better containment of bone graft. ${ }^{13}$ In recent years, the evolution of static interbody fusion cages has emphasized minimally invasive spinal surgery technique (MISST) applications with the primary goal to reduce approach morbidity by improving insertion mode and to control sagittal and coronal alignment better. ${ }^{14-19}$ Consequently, interbody fusion cages of different sizes and shapes were offered. Additional technological advancements included biomaterial components and cage manufacturing processes, such as 3-dimensional printing. ${ }^{20}$ Despite these advances in static cage design, subsidencerelated problems due to endplate violation on insertion remained an issue linked to inferior clinical outcomes. $^{10,21,22}$ These shortcomings stimulated a shift from static to expandable cage technology in an attempt to minimize undersizing of static cages used in posterior lumbar interbody fusion (PLIF), and transforaminal lumbar interbody fusion (TLIF). The first-generation expandable lumbar interbody fusion cages were primarily vertically expandable. ${ }^{23,24}$ Minimizing size during the insertion process was shown to facilitate the application of MISST during insertion while maximizing vertical height restoration. ${ }^{16-19,25}$ Second- and third-generation cage expansion technologies added horizontal expansion to provide a larger footprint and cover more of the endplate. ${ }^{16,26}$ Further advances focused on better controlling sagittal alignment and the ability to place more substantial amounts of bone graft either around the device or into an internal graft chamber. ${ }^{26}$

\section{THE EVOLUTION OF EXPANDABLE INTERBODY CAGES}

The development of expandable cages followed the surgical approaches ranging from lateral to oblique and direct posterior access. Consequently, medial-to-lateral, anterior-to-posterior, vertical, and translating expansion mechanisms have been employed. Early examples of vertical expansion were embodied in the StaXx. ${ }^{27}$ This first-generation expandable poly-ether-ether-ketone (PEEK) cage provides expansion by the sequential insertion of PEEK wafers in situ, creating a stack or column of vertical distraction in 1-mm increments caudad to cephalad. While the StaXx allows intervertebral implantation through a small entry portal, it cannot be retracted once implanted and fully expanded. Also, it does not have a bone graft chamber. Another example of an expandable cage device to be assembled in situ is the modular InFix device. ${ }^{28-30}$ In total, 84 unique configurations are possible with the 3 different footprints, 4 vertical side struts ranging from 8 to $14 \mathrm{~mm}$, and 7 lordotic angles ranging from $0^{\circ}$ to $18^{\circ}$ degrees in $3^{\circ}$ increments. This modular expandable cage design brought several advantages to the operating room. The in situ expansion was shown to reduce endplate trauma and subsequent propagation of subsidence. When fully assembled in situ, this titanium implant was intended to be a load-sharing device resting on the ring apophysis with a lower design-inherent strain limitation at the bone-cage interface. This design include a fenestrated bone graft chamber intended to promote interbody fusion. Moreover, the overall low modulus of elasticity of the InFix device (1099 $\mathrm{MPa})$ was reported to be much closer to cancellous bone $(\approx 220 \mathrm{MPa})$, than the material modulus of elasticity of PEEK (3600 MPa), cortical bone $(12000 \mathrm{MPa})$, titanium $(113800 \mathrm{MPa})$, or cobaltchrome alloys $(234000 \mathrm{MPa}){ }^{30}$ Another early example of vertically expandable is the Omega Lumbar Interbody Fusion Device. ${ }^{31}$ This all-titanium, bullet-nose design facilitated insertion and featured an infinitely adjustable, from 0 to $3 \mathrm{~mm}$, self-locking expansion mechanism for minimal impaction. It also featured a cannulated option for the trans-Kambin triangle lumbar interbody fusion over a guidewire and in standard solid form for PLIF implantation.

Other examples of primarily vertically expanding interbody fusion cages include the Caliber, the Rise, and the Altera. ${ }^{23,24}$ These titanium implants are designed for posterior PLIF and TLIF approaches and intended to deal with reduced height during insertion to minimize impaction and preserve endplate integrity. The Altera (released in 2014) 
features an articulating expandable cage design to be steered into the anterior disc space during TLIF procedures. The VariLift is a threaded cylindrical interbody fusion device that can be used in pairs bilaterally through a PLIF approach or as a single device from a unilateral oblique TLIF approach. ${ }^{32,33}$ Most of these expandable interbody fusion spacers are approved by the US Food and Drug Administration (FDA) for single- or 2-level implantation and are to be used with posterior supplemental fixation systems. ${ }^{32,33}$

The FlareHawk expandable cage features a hybrid design with an outer PEEK shell and an inner titanium shim. ${ }^{34}$ The shell is inserted in a compressed form ideally suited for MISS applications because it can be inserted through a small annular window into the intervertebral disc space and expands bidirectionally when the inner titanium shim is inserted into the PEEK shell.

\section{DRAWBACKS OF EXPANDABLES}

Some disadvantages of expandable interbody fusion cages have been demonstrated in clinical follow-up. Damage to the endplate and the resultant subsidence and loss of intervertebral and neuroforaminal height with recurrence of symptoms can occur with overexpansion, especially in patients with osteopenia or osteoporosis. Stress-shielding and lack of sufficient area for bone grafting may contribute to pseudarthrosis. One of the biggest drawbacks of expandable interbody fusion cages may be related to the increased cost. Clinical research will have to show whether the higher implant cost on the front end of a clinical treatment cycle are justified by perioperative cost savings on the back end due to shorter operative time, fewer complications, and fewer reoperations.

\section{SURGEON INPUT AND DESIGN FEATURES}

Expandable cages have several design features that were prompted by surgeons' desires to solve the problems of prior designs. For example, smaller insertion height helps minimize nerve root retraction and reduces the impaction force require to place the cage in its optimal position. Another feature common to several commercially available expandable interbody fusion cages relates to continuous expansion. This feature is considered advantageous by most surgeons familiar with this technology as it allows optimal endplate-to-endplate fitting while minimizing overdistraction. The in situ distraction and expansion is another such surgeon-preferred feature because the best fit can be combined with optimal height restoration. The combination of PEEK with titanium or cobalt-chrome alloys facilitates radiographic fusion assessment at the bone-implant interface. Likewise, radiographic markers are helpful in ascertaining the exact implant position. Some surgeons prefer an automatic locking mechanism to eliminate an extra locking step and to maintain the desired implant height over time.

\section{MEASURES OF CLIINICAL SUCCESS}

Commonly used clinical and radiographic outcome parameters have been correlated in several clinical studies in an attempt to develop predictors of clinical success with the expandable cage technology. Increase in posterior disc and foraminal height, restoration of lumbar lordosis, the absence of cage subsidence or endplate injury, along with bony bridging on advanced cross-sectional imaging studies including computed tomography are commonly investigated variables. Several clinical studies $^{1-4,6,16,22,23,25-27,35-49}$ and a meta-analysis ${ }^{10}$ on expandable lumbar interbody fusion cages have highlighted the use of these radiographic parameters and how they correlate to commonly used patient self-reported outcome measures.

Early studies were on simple cage designs such as the B-Twin. ${ }^{2-4,35}$ The studies demonstrated the problems with cage subsidence and in expandable devices, which have stress concentration at the bone-implant interface. Other stacked implant designs demonstrated the need for migration resistance. Posterior extrusion was a common complication noted with stacked PEEK designs. ${ }^{36}$ An early comparative prospective randomized controlled clinical and radiological study with enrolling patients in 2 groups, (1) with expandable cage (73 patients) or (2) static cage (72 patients), proved the concept of lower complications during PLIF surgery because of less tissue trauma and fewer problems from retraction of neural tissues. ${ }^{37}$ This clinical trial statistically confirmed a greater increase in anterior disc height ratio $(P=.0057)$, posterior disc height ( $P$ $=.016)$, and segmental lordosis $(P=.00021)$ without loss of correction in follow-up. The authors reported similar radiologic fusion rate of $94.5 \%$ with the expandable and $87 \%$ with the static cage $(P$ 
$>$.2). Long-term 5-year follow-up was published on 72 patients treated with expandable spacers. At final follow-up, the authors reported significant Oswestry Disability Index reductions $(41.5 \pm 3.5 ; P<.05)$. The focal lordosis restoration was maintained without significant difference $(P=.453)$ with a $100 \%$ fusion rate and without adjacent segment degeneration. ${ }^{39}$ Later designs showed favorable clinical outcomes and maintained restoration of neuroforaminal height with expandable PEEK cages. ${ }^{27}$ At average follow-up of 19.3 months, the authors demonstrated a statistically significant increases in the average disk height from 6.49 to $8.18 \mathrm{~mm}(P=.037)$ and foraminal height from 15.6 to $18.53 \mathrm{~mm}(P=.0001)$, and a significant reduction in the anterolisthesis from 5.13 to $3.15 \mathrm{~mm}(P=$ .005 ), and a very low, statistically not significant, vertical subsidence numbers averaging $0.66 \mathrm{~mm}$ $(7.4 \% ; P=.35)$. Correlation with clinical outcomes showed statistically significant reductions in the visual analog scale (VAS) back from 6.42 to $3.11(P$ $<.001)$, in VAS buttock from 4.66 to $1.97(P=$ $.002)$, in VAS leg from 4.55 to $1.96(P<.001)$, and in Oswestry Disability Index from 21.7 to $12.1(P<$ $.001)$. On the basis of these results, the authors concluded that expandable PEEK spacers can "...effectively and durably restore disk and foraminal height and improve the outcome without significant subsidence." 27 Several MISS implantation studies utilizing multiple, different expandable interbody fusion cages in conjunction with percutaneous pedicle screw constructs were demonstrated soon thereafter. ${ }^{1,16,25,41}$

\section{STATIC VERSUS EXPANDABLE}

When looking at clinical outcomes in standard MISS TLIF with static versus expandable cages, several studies have failed to demonstrated superior outcomes with the expandable cage technology. ${ }^{23,25,42,43,49}$ Various geometrical cage configurations including "banana" cage design have been found to be less prone to subsidence and better maintenance of lordosis and sagittal alignment corrections than with straight cage designs. In one study, 33 patients were implanted with an expandable banana-shaped and another 28 with an expandable straight cage. The authors found statistically greater improvements $(P=.03)$ of disc height in the banana group where disc height changed from $4.8 \pm 2.5 \mathrm{~mm}$ to $10.4 \pm 2.4 \mathrm{~mm}$ versus the straight cage group, where posterior disc height changed from $6.2 \pm 2.5 \mathrm{~mm}$ to $9.6 \pm 1.7$ $\mathrm{mm}$. In addition, segmental lordosis angle correction was higher in the banana group with $5.8^{\circ} \pm$ $5.0^{\circ}$ versus $3.7 \pm 3.6^{\circ}$. The lumbar lordotic angle improved in the straight group with $5.2^{\circ} \pm 6.4^{\circ}$ compared to $3.7^{\circ} \pm 5.8^{\circ}$ in the banana group. The subsidence rate was $6.6 \%$ in patients who received the banana-shaped expandable cage and $14.8 \%$ in patients who received the static expandable group. ${ }^{46}$ This study clearly highlights the importance of cage geometry and geometrical stiffness on clinical and radiographic outcome parameters.

Another FDA-registered retrospective clinical trial $^{34}$ reported favorable outcomes on 129 patients with a stent-like implant emphasizing the importance of geometrical configuration of the expandable interbody fusion cage. Follow-up to date indicates that $96.6 \%$ fusion rate based 56 of 58 patients with available postoperative radiographs. Among 45 evaluable subjects, 71\% (32 patients) achieved clinically significant improvements in VAS leg pain, and $76 \%$ (34 patients) achieved clinically significant improvements in VAS back pain. In the absence of complications including subsidence, displacement, and nerve injury attesting to the importance of geometrical configuration of cages capable of both cephalad-caudad and lateral-medial expansion maximize vertebral body endplate coverage and fusion area while minimizing nerve root retraction.

\section{CLINICAL AND BIOMECHANICAL RELEVANCE OF STIFFNESS}

Many parameters have been suggested as clinically relevant indicators of spinal stability. Range of motion is the most commonly used metric with utility in both the clinical and biomechanical setting. For in vivo comparisons of stability (eg, between degenerative conditions and fused spines) range of motion may be readily determined but may not be sufficient in characterizing the efficacy of a given spinal device. A relevant example would be the different responses seen between the fixation device and the response of an functional spinal unit (FSU) when implanted with a motion-preservation device. Because of this, parameters such as stiffness, which incorporate displacement as a function of load, offer both physical relevance and a direct-controlled correlation to stability. A representative loaddisplacement curve for a functional spinal unit can be found in Figure 1. 


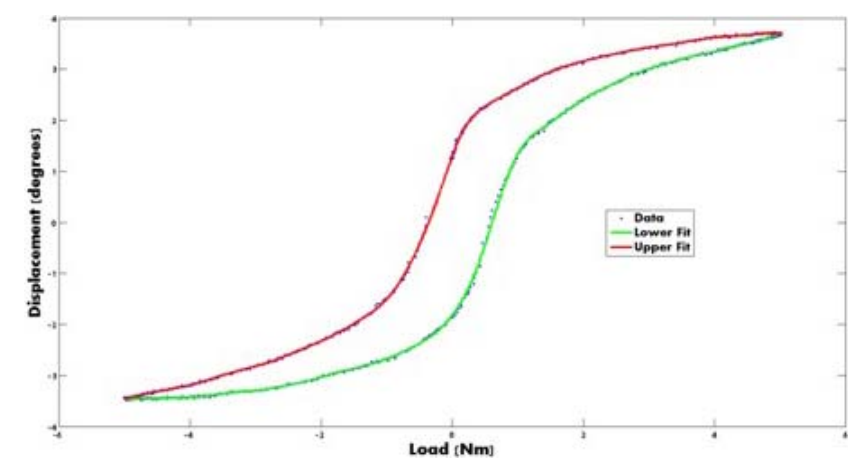

Figure 1. Representative load-displacement curve for a functional spinal unit.

\section{EFFECTIVE STIFFNESS OF COMPOSITE DEVICES}

Spinal interbody fusion devices have traditionally been designed and manufactured from homogenous materials. Examples include commercially pure titanium and titanium alloys. The device properties are dependent upon intrinsic material properties (eg, modulus of elasticity or stiffness), while the implant construct exhibits a design-dependent construct stiffness along with those material properties. In devices that incorporate different materials, an effective stiffness should be used in the modeling of the construct stiffness and, generally, can include a "springs-in-series" type of stiffness model for a single device with multiple layers of differing materials. Current titanium and PEEK polymer combination falls into multi-material device designs. In the case of numerous interbody devices (ie, 2 interbody cages) with various design materials, the appropriate, sufficient stiffness could be modeled as springs in parallel with each spring modeled in series. Combinations of devices and materials make for various spring models for an overall construct stiffness.

\section{CONCLUSIONS}

Ease of implantation in surgery and superior clinical outcomes are 2 of the many key requirements for surgeons to favor one implant over another. Spine surgeons are keenly aware that implant stiffness and spinal stability are the foundation of successful fusion. Common problems with both static and expandable interbody fusion cage implants include migration, expulsion, subsidence, and nonunion. Minimally invasive application through small access portals substantiates the need for expandable implants as they bridge the gap between the small size required during insertion, and the maximum size desired for optimum anterior column support. Important metrics relative to spinal stability include the stiffness of native materials along with the stiffness of an implant. Material stiffness is a fundamental material property with specific requirements. The stiffness of materials requires empirical derivation from homogenous isotropic test coupons. The same material configured in the form of a spinal implant has a different construct stiffness when compared to the native material, that is, a construct stiffness that is dependent upon the configuration of an implant and not the intrinsic native material property. Although both are commonly referred to as "stiffness," a material's intrinsic property is different when configured as a medical device and loaded as is the overall FSU when implanted with the implant. All reflect a specific response given the same unit load. Surgeons must consider this relationship between effective stiffness of the implant in its final expanded position and the patient-inherent factors that dictate the final size and implant to endplate interactions that may impact clinical outcomes. Open architecture expandable cage designs that allow vertical and medial-to-lateral increase in size appear the most suitable for successful clinical application since the final construct stiffness is likely sufficient to provide immediate anterior column support while accommodating reduced sizes required for minimally invasive surgery applications.

\section{REFERENCES}

1. Morgenstern R, Morgenstern C. Feasibility of full percutaneous segmental stabilization of the lumbar spine with a combination of an expandable interbody cage and an interspinous spacer: preliminary results. Int J Spine Surg. 2018;12(6):665-672.

2. Zhang DQ, Yang Q, Jiang CM, et al. [Comparison of treatment with micro endoscopic discectomy and posterior lumbar interbody fusion using single and double B-Twin expandable spinal spacer]. Zhonghua Wai Ke Za Zhi. 2010;48(21):1637-1641.

3. Yao N, Wang W, Liu Y. Percutaneous endoscopic lumbar discectomy and interbody fusion with B-Twin expandable spinal spacer. Arch Orthop Trauma Surg. 2011;131(6):791-796.

4. Zhang X, Wang Y, Xiao S, et al. [Preliminary clinical results of endoscopic discectomy followed by interbody fusion using B-Twin expandable spinal spacer]. Zhongguo Xiu Fu Chong Jian Wai Ke Za Zhi. 2011;25(10):1153-1157.

5. Lewandrowski KU, Ransom NA, Ramirez Leon JF, Yeung A. The concept for a standalone lordotic endoscopic wedge lumbar interbody fusion: the LEW-LIF. Neurospine. 2019;16(1):82-95.

6. Lewandrowski KU. Surgical technique of endoscopic 
transforaminal decompression and fusion with a threaded expandable interbody fusion cage and a report of 24 cases. Journal of Spine. 2018;7(2).

7. Lewandrowski KU. Successful outcome after outpatient transforaminal decompression for lumbar foraminal and lateral recess stenosis: the positive predictive value of diagnostic epidural steroid injection. Clin Neurol Neurosurg. 2018;173:3845.

8. Lewandrowski KU. Readmissions after outpatient transforaminal decompression for lumbar foraminal and lateral recess stenosis. Int J Spine Surg. 2018;12(3):342-351.

9. Lewandrowski KU. Incidence, management, and cost of complications after transforaminal endoscopic decompression surgery for lumbar foraminal and lateral recess stenosis: a value proposition for outpatient ambulatory surgery. Int $J$ Spine Surg. 2019;13(1):53-67.

10. Alvi MA, Kurian SJ, Wahood W, Goyal A, Elder BD, Bydon M. Assessing the difference in clinical and radiologic outcomes between expandable cage and nonexpandable cage among patients undergoing minimally invasive transforaminal interbody fusion: a systematic review and meta-analysis. World Neurosurg. 2019;127:596-606 e591.

11. Fujimori T, Le H, Schairer WW, Berven SH, Qamirani E, Hu SS. Does transforaminal lumbar interbody fusion have advantages over posterolateral lumbar fusion for degenerative spondylolisthesis? Global Spine J. 2015;5(2):102-109.

12. Humphreys SC, Hodges SD, Patwardhan AG, Eck JC, Murphy RB, Covington LA. Comparison of posterior and transforaminal approaches to lumbar interbody fusion. Spine (Phila Pa 1976). 2001;26(5):567-571.

13. Zhang W, Duan L, Shang X, Xu X, Hu Y, He R. [Effectiveness of minimally invasive transforaminal lumbar interbody fusion assisted with microscope in treatment of lumbar degenerative disease]. Zhongguo Xiu Fu Chong Jian Wai Ke Za Zhi. 2013;27(3):268-273.

14. Choi WS, Kim JS, Hur JW, Seong JH. Minimally invasive transforaminal lumbar interbody fusion using bananashaped and straight cages: radiological and clinical results from a prospective randomized clinical trial. Neurosurgery. 2018;82(3):289-298.

15. Choi WS, Kim JS, Ryu KS, Hur JW, Seong JH. Minimally invasive transforaminal lumbar interbody fusion at L5-S1 through a unilateral approach: technical feasibility and outcomes. Biomed Res Int. 2016;2016:2518394.

16. Kim CW, Doerr TM, Luna IY, et al. Minimally invasive transforaminal lumbar interbody fusion using expandable technology: a clinical and radiographic analysis of 50 patients. World Neurosurg. 2016;90:228-235.

17. Li XC, Huang CM, Zhong CF, Liang RW, Luo SJ. Minimally invasive procedure reduces adjacent segment degeneration and disease: new benefit-based global meta-analysis. PLoS One. 2017;12(2):e0171546.

18. Parker SL, Mendenhall SK, Shau DN, et al. Minimally invasive versus open transforaminal lumbar interbody fusion for degenerative spondylolisthesis: comparative effectiveness and cost-utility analysis. World Neurosurg. 2014;82(1-2):230238.

19. Patel AA, Zfass-Mendez M, Lebwohl NH, et al. Minimally Invasive Versus Open Lumbar Fusion: A Comparison of blood loss, surgical complications, and hospital course. Iowa Orthop J. 2015;35:130-134.
20. McGilvray KC, Easley J, Seim HB, et al. Bony ingrowth potential of 3D-printed porous titanium alloy: a direct comparison of interbody cage materials in an in vivo ovine lumbar fusion model. Spine J. 2018;18(7):1250-1260.

21. McAfee PC, DeVine JG, Chaput CD, et al. The indications for interbody fusion cages in the treatment of spondylolisthesis: analysis of 120 cases. Spine (Phila Pa 1976). 2005;30(6 Suppl):S60-65.

22. Zhang J, Pan A, Zhou L, Yu J, Zhang X. Comparison of unilateral pedicle screw fixation and interbody fusion with PEEK cage vs. standalone expandable fusion cage for the treatment of unilateral lumbar disc herniation. Arch Med Sci. 2018;14(6):1432-1438.

23. Boktor JG, Pockett RD, Verghese N. The expandable transforaminal lumbar interbody fusion - two years follow-up. J Craniovertebr Junction Spine. 2018;9(1):50-55.

24. Mantell M, Cyriac M, Haines CM, Gudipally M, O'Brien JR. Biomechanical analysis of an expandable lateral cage and a static transforaminal lumbar interbody fusion cage with posterior instrumentation in an in vitro spondylolisthesis model. J Neurosurg Spine. 2016;24(1):32-38.

25. Hawasli AH, Khalifeh JM, Chatrath A, Yarbrough CK, Ray WZ. Minimally invasive transforaminal lumbar interbody fusion with expandable versus static interbody devices: radiographic assessment of sagittal segmental and pelvic parameters. Neurosurg Focus. 2017;43(2):E10.

26. Qandah NA, Klocke NF, Synkowski JJ, et al. Additional sagittal correction can be obtained when using an expandable titanium interbody device in lumbar Smith-Peterson osteotomies: a biomechanical study. Spine J. 2015;15(3):506-513.

27. Alimi M, Shin B, Macielak M, et al. Expandable polyaryl-ether-ether-ketone spacers for interbody distraction in the lumbar spine. Global Spine J. 2015;5(3):169-178.

28. Buttermann GR, Beaubien BP, Freeman AL, Stoll JE, Chappuis JL. Interbody device endplate engagement effects on motion segment biomechanics. Spine J. 2009;9(7):564-573.

29. Kanayama M, Cunningham BW, Haggerty CJ, Abumi $\mathrm{K}$, Kaneda K, McAfee PC. In vitro biomechanical investigation of the stability and stress-shielding effect of lumbar interbody fusion devices. J Neurosurg. 2000;93(2 Suppl):259-265.

30. Ledet EH, Tymeson MP, Salerno S, Carl AL, Cragg A. Biomechanical evaluation of a novel lumbosacral axial fixation device. J Biomech Eng. 2005;127(6):929-933.

31. Hockley A, Ge D, Vasquez-Montes D, et al. Minimally invasive versus open transforaminal lumbar interbody fusion surgery: an analysis of opioids, nonopioid analgesics, and perioperative characteristics. Global Spine J. 2019;9(6):624-629.

32. Barrett-Tuck R, Del Monaco D, Block JE. One and two level posterior lumbar interbody fusion (PLIF) using an expandable, stand-alone, interbody fusion device: a VariLift((R)) case series. J Spine Surg. 2017;3(1):9-15.

33. Emstad E, Del Monaco DC, Fielding LC, Block JE. The VariLift((R)) Interbody Fusion System: expandable, standalone interbody fusion. Med Devices (Auckl). 2015;8:219-230.

34. Coric D. Transforaminal/posterior lumbar interbody fusion with the FlareHawk ${ }^{\circledR}$ expandable interbody fusion device: a retrospective chart review study. In: Administration FaD, ed2019.

35. Park JH, Bae CW, Jeon SR, Rhim SC, Kim CJ, Roh SW. Clinical and radiological outcomes of unilateral facetectomy and interbody fusion using expandable cages for 
lumbosacral foraminal stenosis. $J$ Korean Neurosurg Soc. 2010;48(6):496-500.

36. Kim PD, Baron EM, Levesque M. Extrusion of expandable stacked interbody device for lumbar fusion: case report of a complication. Spine (Phila Pa 1976). 2012;37(18):E1155-1158.

37. Korovessis P, Repantis T, Baikousis A, Iliopoulos P. Posterolateral versus circumferential instrumented fusion for monosegmental lumbar degenerative disc disease using an expandable cage. Eur J Orthop Surg Traumatol. 2012;22(8):639645.

38. Lau D, Song Y, Guan Z, La Marca F, Park P. Radiological outcomes of static vs expandable titanium cages after corpectomy: a retrospective cohort analysis of subsidence. Neurosurgery. 2013;72(4):529-539; discussion 528-529.

39. Liu E, Yin Q, Guo D. [Long-term follow-up study on expandable Cage in treatment of degenerative lumbar disease]. Zhongguo Xiu Fu Chong Jian Wai Ke Za Zhi. 2014;28(5):540543.

40. Cannestra AF, Peterson MD, Parker SR, Roush TF, Bundy JV, Turner AW. MIS expandable interbody spacers: a literature review and biomechanical comparison of an expandable MIS TLIF with conventional TLIF and ALIF. Spine (Phila Pa 1976). 2016;41 Suppl 8:S44-49.

41. Coe JD, Zucherman JF, Kucharzyk DW, Poelstra KA, Miller LE, Kunwar S. Multiexpandable cage for minimally invasive posterior lumbar interbody fusion. Med Devices (Auck1). 2016;9:341-347.

42. Kale A, Oz, II, Onk A, Kalayci M, Buyukuysal C. Unilaterally posterior lumbar interbody fusion with double expandable peek cages without pedicle screw support for lumbar disc herniation. Neurol Neurochir Pol. 2017;51(1):53-59.

43. Yee TJ, Joseph JR, Terman SW, Park P. Expandable vs static cages in transforaminal lumbar interbody fusion: radiographic comparison of segmental and lumbar sagittal angles. Neurosurgery. 2017;81(1):69-74.

44. Massie LW, Zakaria HM, Schultz LR, Basheer A, Buraimoh MA, Chang V. Assessment of radiographic and clinical outcomes of an articulating expandable interbody cage in minimally invasive transforaminal lumbar interbody fusion for spondylolisthesis. Neurosurg Focus. 2018;44(1):E8.

45. Mica MC, Voronov LI, Carandang G, Havey RM, Wojewnik B, Patwardhan AG. Biomechanics of an expandable lumbar interbody fusion cage deployed through transforaminal approach. Int J Spine Surg. 2018;12(4):520-527.

46. Tassemeier T, Haversath M, Jager M. Transforaminal lumbar interbody fusion with expandable cages: radiological and clinical results of banana-shaped and straight implants. $J$ Craniovertebr Junction Spine. 2018;9(3):196-201.

47. Godzik J, Lehrman JN, Newcomb A, et al. Tailoring selection of transforaminal interbody spacers based on biomechanical characteristics and surgical goals: evaluation of an expandable spacer. J Neurosurg Spine. 2019:1-7.

48. Vaishnav AS, Saville P, McAnany S, et al. Retrospective review of immediate restoration of lordosis in single-level minimally invasive transforaminal lumbar interbody fusion: a comparison of static and expandable interbody cages. Oper Neurosurg (Hagerstown). 2020;18(5):518-523.

49. Khechen B, Haws BE, Patel DV, et al. Static versus expandable devices provide similar clinical outcomes following minimally invasive transforaminal lumbar interbody fusion. HSS J. 2020;16(1):46-53.

Disclosures and COI: The views expressed in this article represent those of the authors and no other entity or organization. The authors have no conflict of interest in regards to this research. KUL and $\mathrm{BC}$ have nothing to disclose.

Corresponding Author: Kai-Uwe Lewandrowski, MD, Staff Orthopaedic Spine Surgeon, Center for Advanced Spine Care of Southern Arizona and Surgical Institute of Tucson, 4787 E. Camp Lowell Drive, AZ 85712. Phone (520) 2041495; Email: business@tucsonspine.com.

Published 9 December 2020

This manuscript is generously published free of charge by ISASS, the International Society for the Advancement of Spine Surgery. Copyright (C 2020 ISASS. To see more or order reprints or permissions, see http://ijssurgery.com. 